\title{
Leadership's Thinking Process with Contextual Intelligence in Executing Diversification Strategy
}

\author{
Caren B. Scheepers, Camrin Roberts Maher \\ Gordon Institute of Business Science, University of Pretoria, South Africa \\ scheepersc@gibs.co.za, camrinmaher@gmail.com
}

\begin{abstract}
Diversification is a popular strategy for growth in response to a volatile economy. Current research, however, devotes little attention to the leadership required to ensure successful diversification, except for theoretical contributions on leaders' thinking processes from scholars within the strategy discipline. This study thus conducted fieldwork in South African organisations to explore empirically how senior leaders' thinking processes, demonstrating contextual intelligence, contributing to successful diversification. A qualitative study was conducted by collecting data through semi-structured interviews from 15 executives with an average of 21 years' experience in senior management roles, who had been involved in diversification in South Africa. A critical incident interview technique was used, and interviewees offered examples of how they changed their way of thinking in creating an environment for successful diversification. The analysis revealed that continuous change was required to successfully implement a diversification strategy. Leaders demonstrated specific thinking processes, for example: being intently aware of their context, they filtered and compared this information to their schema or preconceived cognitive representations. In case of a mismatch, they changed their way of thinking; and directed contextual information to challenge others' current way of thinking. Surprising findings included leaders' sensing other's emotions and appealing to these through storytelling to elicit support for their diversification. Diversification requires organisations to invest in developing the agility and global perspective of leadership to increase awareness of trends in their context, their own biases and to shift their mindsets as well as purposefully challenging other's thinking.
\end{abstract}

Keywords: Strategy Management; Leadership; Contextual Intelligence; Complexity Theory; Diversification; Dominant logic; Decision-making; Cognitive Psychology.

\section{Introduction}

Competitive advantage is no longer sustainable over the long haul but is achieved through continually creating, eroding, destroying and recreating it through strategic manoeuvring (D'Aveni 1994; D'Aveni, Dagnino \& Smith 2010). One of the strategic manoeuvres an organisation can employ, suggested by Stern and Henderson (2004), is diversification, to adapt faster to environmental changes. Diversification involves a strategic change in more than merely product ranges or exploring new markets, instead it includes both (Ansoff 1958). While diversification is strategically important, limited research has been conducted on leaders' thinking processes to execute a diversification strategy. The objective of this study is thus to explore, how do leaders in organisations with successful diversification strategies think about their contexts; and how do their thinking processes then influence their organisations' diversification? Scholars in the strategy discipline, namely Bettis, Hall and Prahalad, in their seminal work already in 1978, argued that the quality of leadership thinking was as critical in explaining performance in diversification as any other factor, yet limited empirical studies explored the role of leadership in diversification processes.

Lau, already in 1993 and later Mumford et al. (2000), contend that diversification is different to other strategies since, it requires a fit between strategy and organisational characteristics, which include leaders' characteristics and mindsets. In this regard, Kofman and Senge's, (1993) classic concept of a learning organisation, urge leaders to shift their current ways of thinking, classifying and assimilation of information to fit the organisational context. In his turn, Azmi, (2008) advocates for an intentional, active and planned attempt towards strategic rethinking, with a conscious decision to clear out knowledge that had been producing insufficient outcomes. Weeks, (2007) contends that fundamental transformation of strategic leadership thinking is required. These scholars advocate for research in thinking processes associated with strategy management since there is limited empirical research in this area and the present study adheres to this call. Weeks, (2007) specifically advise that leaders conceptualise the business environment as an ecosystem of various interacting contextual determinants that collectively impact on business. Mayo and Nohria, (2005) also argued that there is a connection between business performance and the context understood by leadership. 
The ability to diagnose context, and identify its variables, is thus an important competency for leaders to operate effectively (Kutz, 2008) within a volatile, uncertain, complex and ambiguous (VUCA) economy, as defined by Bennet and Lemoine (2014). Prahalad (2004), Prahalad and Bettis (1986) Bettis and Hitt, (1995) and Grant, (1988) reason that performance of diversified firms can be improved through leadership's application of their intelligence, which they referred to as dominant logic or the filtering of information that supports the logic or main reasoning about what causes the organisation to be successful. While these scholars offered valuable models that linked constructs like the dominant logic of leadership's thinking processes with successful diversification, the present study set out to examine empirically how these complex conceptual models function in practice.

\section{Literature Review}

Diversification Strategy: Diversification was introduced in the fifties by Ansoff (1958), in his classic growth strategy matrix, and has since attracted a plethora of strategic management research (Chandler 1990; Ramanujam \& Varadarajan 1989; Rumelt 1974). Diversification differs from other strategies in that it requires new skills and techniques. Lau, (1993) furthers Ansoff's (1958) argument that the implementation of a diversification strategy requires a fit between strategy and leaders' mindsets. Hutzschenreuter and Horstkotte, (2013) admit that even though diversification itself is complex, the amount of complexity that it brings is likely to differ, depending on the changing context. Penrose and Pitelis (2002), reason that firms that diversify require leaders with experience-based knowledge, akin to tacit knowledge, and firm-specific capabilities. Amongst the four types of product market strategies, illustrated in the table below, Ansoff (1958) found that diversification stands apart, as it invariably leads to physical and organisational changes in the structure and functioning of the business, which represents a break with past business experiences.

Table 1: Ansoff Growth Matrix

\section{Business Growth Description}

Alternatives

Market penetration

Increase market share for a firm's products in the existing market, whilst remaining with the original product-market strategy. Increasing volume to new or existing customers can increase sales.

Market development Finding and developing new markets for current product lines. This entails adapting the business strategy of the current product lines to these markets.

Product development Enhancing the current products to the current market, through improved changes to the existing offering.

Diversification Develop new product markets in addition to the existing business.

* Due to expansion into new markets/ customers as well as developing new products; this business growth strategy is the most disruptive to the current organisational structures and resources.

Source: Adapted from Ansoff (1958)

Ansoff, (1988) emphasised, though, that in most situations, a well-run organisation would follow several of these paths simultaneously, like market penetration, market development and product development. He advised that this approach predicts the survival of the firm in the face of economic competition. Prahalad and Bettis (1986) and in subsequent works (Bettis \& Prahalad 1995; Prahalad \& Bettis 2000; Prahalad 2004;), advocate that the insight and vision of top leadership is the key to successful diversification. It is thus not necessarily the product-market diversity, but rather the strategic logic of leadership that influences firm performance. This implies that diversified firms without this capability may not perform well. Prahalad and Bettis, (1986) presented a framework in which dominant logic is a primary characteristic of leadership in a diversified firm, defining it as a "mindset or a worldview and conceptualisation of the business and administrative tools to accomplish goals and make decisions in that business" (Prahalad \& Bettis 1986, p. 41). In later publications, Bettis and Prahalad (1995) reason that dominant logic is thus an antecedent for strategic change, for it allows the organisation to strike a balance between the need for direction and control, and adherence to the strategy. Lampel and Shamsie, (2000) note that as corporations expand in size and complexity, dominant logic indeed offers leadership a framework that assists them in providing direction and support to their followers. The impact of diversification on a firm and its performance is varied and complex. 
It is affected by variables such as related versus unrelated diversification, capability of top managers, industry structure and the mode of diversification (Pandya \& Rao, 1998).

Jarzabkwoski, (2001) posits that diversification also enables the flexibility and speed needed to adjust to contexts changes. However the trick to strategy, according to Levy, (2007) is to know when to make a move; a balance needs to be struck between moving too quickly and too late. Understanding this is key when diagnosing the context of a situation and adapting by diversifying. As the knowledge-based economy grows, environmental instability increases and unanticipated events occur, which fundamentally change the context in which institutions function. New ways of dealing with this complexity and chaotic contexts are needed (Drejer 2004). Consequently, the ability to change rapidly and continuously, especially by developing new products, is not only required as a core competence, it is also essential at the heart of company cultures, enabling them to compete and transform (Brown \& Eisenhardt 1997; Chakravarthy 1997). Prahalad (2004), in contrast to his earlier scholarly work, considered the velocity of environmental change as decisive in whether dominant logic is ultimately beneficial or negative for a firm, arguing that should the environment be subject to rapid changes, "the blinders of dominant logic may make it hard to recognise new threats and opportunities" (Prahalad 2004, p. 172). He further reasoned that for organisations to succeed with strategic change such as diversification, leaders need to have peripheral vision and flexibility that can keep up with the dynamic changes of the environment and ideally anticipate them.

It requires leaders to discard their current dominant logic and develop a new, more relevant one, in obtaining a distinct competitive advantage. His reasoning was that best practices only show what had been done, and likened it to a current dominant logic, whereas a new dominant logic may be required. Grant (1988), Jarzabkowski (2001) as well as Von Krogh and Roos (1996) supported this, arguing that leaders need to have self-reference, built upon existing knowledge banks, which they apply within a context. Should these selfreference concepts or schemas not be relevant, they need to utilise their intelligence to adapt and form new ones. Schemas represent a repertoire of tools, beliefs, theories, values and propositions that have developed over time through leaders' personal experiences and exposure (Prahalad \& Bettis, 1986; 2000), enabling them to categorise an event, assess its consequences and consider appropriate actions relatively quickly. Nonetheless, it is hard for an individual to let go of attachments, with human error and biases likely to occur (Tsang \& Zahra 2008). Bettis, Wong and Blettner, (2003) as well as Prahalad, (2004) reasoned though that dominant logic can and does breed success, as long as the environment stays stable; but when faced with radical changes, the path dependencies that the individual has may lead to fatal cognitive entrapment, rendering the ability to adapt virtually impossible. Since this contingency seems important and current literature depicts organisational context as being highly volatile, the present study undertakes to gain an understanding of how senior leaders perceive their contexts.

Leadership Enabling Diversification: Vermeulen and Barkema, (2002) argue that rapid diversification does not enable learning due to the rapid speed of change, and as Kor and Leblecici, (2005) found, eventually overextends leaders, creating bottlenecks and ultimately leading to poorly adapted structures. Frisina and Frisina, (2011) also maintain that leadership behaviour is a central predictor to individual employees and organisational performance. Marx, (2013) advocates for an integrated view of leadership and strategy, where the analytical, interpersonal, and decision-making skills of leaders are acknowledged as core functions. The present study thus reviewed leadership literature to gain an understanding of how leadership might enable successful diversification, as an important context. Leadership scholars identified a lack of contextual diagnosis, especially within the volatile dynamics of the global economy, and therefore introduced leadership concepts based on non-Newtonian frameworks, such as chaos theory (Burns 2002; Tetenbaum \& Laurence 2011), adaptive capacity (Heifetz, 1998) and complexity theory (Uhl-Bien et al., 2006).

The overarching criticism of traditional and charismatic leadership theories is that they lack contextual consideration, which limits their application, hence Osborn et al. (2002), and Uhl-Bien and Marion (2009), argue that leadership is embedded in the context within which it operates, which acts as a trigger for specific leadership facets. Kutz and Bamford-Wade (2013, p.8) describe context as, "the interwoven and tied together the fabric of a situation, which creates an intricate and unique appearance" Kellerman (2013) declares that contextual intelligence is of paramount importance to leadership, even more than emotional intelligence. To diagnose context, leaders must be cognitively aware of the interactions and interdependencies of the 
situation, with a global perspective, while they consider and operate within local circumstances (Kutz 2008). Ireland and Hitt (2005) agree that globalised thinking is essential. To diagnose context accurately an individual's current thinking may have to shift (Kofman \& Senge 1993).

Mayo and Nohria (2005), also emphasise contextual sensitivity of leaders to understand an evolving environment, capitalise on trends, align resources with objectives and move with the flow of events to implement the strategy. Blass and Ferris, (2007) call this skill contextual learning. Kutz, (2008) contributes that contextual leadership intelligence is an ability to grasp relevant elements from the past, being aware of the present contextual variables and knowing what the future should be like. This orientation to time had not received adequate attention in leadership literature (Thomas \& Greenberger 1995). In turn, Osborn et al. (2002) seminal study towards a contextual theory of leadership, explains that leaders attempt to influence others within their environment by directing what is seen and analysed. They called this emergent dimension, patterning of attention since it includes discussing what is important, not dictating what to do or how to do it. Osborn's later research indicates that leaders' facilitation of dialogue transforms tacit knowledge into collective understanding (Osborn \& Marion 2009). Lord and Maher, (2002) emphasise that leaders connect others to a broad variety of potential information sources. Knowing how is the scholastic measure of intelligence, applicable in situations that are predictable or repeatable, whereas the knowing what is contextbased intelligence needed in unpredictable, novel or unexpected situations (Kutz \& Bamford-Wade 2013).

\section{Methodology}

Given the literature review on diversification and leadership, the research questions in this study are summarized as follows:

Research Question 1: How are leaders in diversifying organisations describing their contexts?

Research Question 2: How are leaders' thinking processes enabling diversification?

Research Approach: The nature of the research questions required a deeper understanding of phenomena. This study thus utilised what Saunders and Lewis, (2012) and Creswell, (2014) refer to as an exploratory approach, focusing on conducting a detailed analysis of the existing literature and conducting interviews. This research was unfolding in nature, making it more suited to a qualitative study (Punch, 2002). The researchers used semi-structured interviews, which offered the opportunity to inquire about themes, to probe and ask additional questions to garner a more profound understanding of the answers of the participant (Saunders \& Lewis 2012). Since the leadership literature above emphasised thinking processes, while contextualizing leadership in a dynamic environment, the present study explored how these thinking processes of leaders might enable successful diversification. The researchers applied the critical incident technique, a flexible set of procedures used for obtaining facts concerning behaviour in defined situations (Flanagan, 1954). For example, the typical question was, "Tell me about an incident where you had to take a decision on diversification: what led to the incident what did you take into account and what was the outcome?" The technique that was applied during the data collection was scheduled and unscheduled probes, enabling the researcher to draw out more complete narratives specific to particular topics (Qu \& Dumay, 2011).

Research Sample: Since the purpose of this study was to explore the thinking processes of leadership, involved in diversification, the targeted population had to be senior managers in corporate organisations, which were executing a diversification strategy. The business environment had to be complex and volatile. Because an emerging economy such as South Africa can be described as particularly ambiguous, and complex with high uncertainty (HSBC, 2016), the South African business environment formed the context of the study. In order to achieve data saturation and representative sample size, Guest, Bunce and Johnson (2006) recommend that for semi-structured interviews a minimum sample size of 12 is required. There were thus 15 interviews conducted in the current study. This enabled the researchers to explore significant occurrences, as identified by the theory and participant, in terms of the management of such incidents and the outcomes or perceived effects.

The information provided enabled the researchers to understand the incident, taking into account cognitive, affective and behavioural elements. The population for this study thus had the following inclusion criteria as boundary (Robinson, 2014): Individuals within a leadership role; between the ages of $30-60$; employed by 
an organisation following, or have followed a diversification strategy within the last five years; senior management role; minimum of three years' experience within the current role / similar role. The sample consisted of 14 males and one female, reflecting the current demographics of senior managers in the South African workplace, ranging in age from 31 to 53, with an average of 21 years' experience. Seven of the interviewees were CEOs; six were directors or executives of either new business or strategy; one senior consultant and one head of the business. Judgement sampling was adopted as a screening measure, to ensure that the leaders had been through a diversification strategy at a senior level. It was thus a non-probability and purposive sample. The interviewees were from 15 different organisations across nine different sectors, for example, pharmaceutical, banking, insurance, finance, manufacturing, FCMG, ITC, consulting, logistics and advertising. While the researchers did not use objective performance measures to establish whether the organisations were successful in their diversification strategy, the participants' perception was that they were successful.

Data Analysis: Guest, Bruce and Johnson, (2006) found that for this type of population selection, the first 12 interviews are sufficient to achieve saturation of codes and themes; therefore, the variety and expanse of the proposed sample pool should provide for adequate data analysis to be done. The researchers used a qualitative data analysis programme, Atlas ti to assist in the coding, categorising and discovery of relationships to shape the data analysis process. The initial 81 codes were refined to 63 , by creating concept families to categorise the data (Spiggle, 1994). Data saturation was reached at 13 interviews when limited new information could be generated. Since the interviews had already been scheduled, they were still conducted.

\section{Findings}

Research Question 1: How Are Leaders in Diversifying Organisations Describing their Contexts: Ansoff, (1988) identified specific vectors to enable diversification, namely vertical integration, horizontal integration, concentric integration and conglomerate diversification, as described in table 2 below. From the interview transcripts the researchers established that the interviewees' descriptions of their organisation's diversification strategies represented Ansoff's (1988) vectors and mostly used more than one vector in their diversification strategy, for example, six organisations used three of the four strategies, as table 2 illustrates.

Table 2: Vectors of Diversification

\begin{tabular}{|c|c|c|}
\hline $\begin{array}{l}\text { Diversification } \\
\text { Growth Vector }\end{array}$ & Description & $\begin{array}{ll}\text { Vectors used } & \text { by } \\
\text { Companies } & \text { in } \\
\text { Sample } & \end{array}$ \\
\hline Vertical integration & $\begin{array}{l}\text { The organisation moves into or acquires suppliers / } \\
\text { customer's areas of expertise to ensure the supply or use of } \\
\text { its own products and services }\end{array}$ & \\
\hline $\begin{array}{l}\text { Horizontal integration } \\
/ \quad \text { related } \\
\text { diversification }\end{array}$ & $\begin{array}{l}\text { New products (technology unrelated) are introduced to } \\
\text { current markets with the realisation of economies of scope } \\
\text { and integration. }\end{array}$ & 2 \\
\hline Concentric integration & $\begin{array}{l}\text { Products that are closely related to current products are } \\
\text { introduced into the current and / or new markets, leveraging } \\
\text { off the companies' technical know-how to gain an advantage. }\end{array}$ & 6 \\
\hline $\begin{array}{l}\text { Conglomerate } \\
\text { diversification }\end{array}$ & $\begin{array}{l}\text { Completely new products are introduced into new markets } \\
\text { (technologically unrelated) }\end{array}$ & 6 \\
\hline
\end{tabular}

Source: Adapted from (Ansoff, 1988)

The interviewees indicated that when there was a higher degree of diversification, the complexity in their context increased. Complexity referred to the number of variables or aspects to consider and the interrelationships between these variables or aspects that increased. In these instances, even more, attention was required from the leaders in the organisation to offer direction and clarify 'why' they were diversifying. For example, an interviewee emphasised, "getting the 'why' right". In describing their contexts, the interviewees mentioned the external market conditions that created the need for change, as well as internal organisational contexts like the employees that were required to adapt, for example, an interviewee 
observed, "it is a continuous process". The requirement of continuous change was thus identified as a theme in enabling a diversification strategy. Interviewees were acutely aware of the challenges in the South African context, such as the low Gross Domestic Product (GDP) and rating agencies' negative perception. Several reported on their difficulties in expanding their businesses into the rest of Africa; prompting them to divest from non-profitable markets.

Question 2: How Are Leaders' Thinking Processes Enabling a Diversification Strategy: From the rich dataset, the researchers derived several themes that described the capacity that enabled diversification? The researchers identified broad categories of codes that linked to enabling diversification. Five of these highlevel themes are listed in the section below and in the summary table (table 3), more quotes are offered per theme.

Theme 1: Obtaining Cognitive Awareness of Context: Interviewees had an acute awareness of the context of operation and their diagnosis of it, and it had a direct impact on their decisions. For example, an interviewee advised that one needs to keep "evolving due to the nature of the business environment". In this regard, the interviewees perceived opportunities in the context as one of the codes that were most frequently reported. These opportunities enhanced the competitive advantage which the diversification strategy ultimately sought. Diagnosing context was thus awareness of the current opportunities, but also looking to the future, enabling agility and speed to be first to market, which positively influenced diversification. The researchers thus identified the focus on time in terms of past, present and future, with a greater emphasis on the future. Another code that frequently came up was purposefully diagnosing context.

The interviewees referred to "the right vantage point" in the interviews, as well as having an "intimate knowledge" of South Africa. The interviewees were also highly aware of the fact that context influenced their decision making. The code for external context (outside of the organisation) was more frequently mentioned than the code for internal context. For example, an interviewee reported that "one needs to keep evolving due to the nature of the business environment." In the diagnosis of context, aspects such as, "knowing when and knowing what", enabled interviewees to select products or refine products for diversification. An interviewee reported ability of "absorbing information at a much faster pace, and knowing what is relevant and what is not". The ability to diagnose context and its impact played a key role in driving the success of a diversification strategy.

Theme 2: Translating Awareness into Context Knowledge: The researchers identified that interviewees went further than awareness they actually gained knowledge from being in tune with context. Interviewees reported that they remained open-minded to the changes in context and were willing to gain knowledge from the dynamics. The interviewees furthermore reported a need to be open to "different perspectives", striking a balance between their own views and those of others. The researchers observed that the willingness to learn was mentioned most frequently by interviewees. These types of quotes in the transcripts were categorised under the theme of learning. For example, interviewees indicated that they were "learning from exposure to other leaders". They extracted best practices or behaviours and applied them to their own context. Through this exposure, a process of reinvention or re-imagination occurred that allowed them to adapt to the dynamics of the context and required diversification. Several interviewees observed evolution in their own awareness, through reflection on their past experiences, which shaped their mindsets. Learning from mistakes formed a tacit knowledge or, according to an interviewee, "a kind of muscle memory". The researchers observed surprisingly that the interviewees had an acute awareness of other people's emotions and their needs; for example, interviewees were focused on whether employees had "an appetite for being stretched".

Theme 3: Influencing Others' Focus on Context: An interviewee observed, "It's more about the contextual issues of the current situation, which will make data or information important". Another called the focus on certain information an "influence technique", to obtain buy-in of individuals towards the strategic goal of diversification. It was noteworthy that asking the right questions were not limited to the situation between leader and subordinate, but also applied by leaders to those outside of this immediate relationship, to enable them to better understand the context and get perspective on the diversification. Asking the right questions and "zoning in on certain things" provided a clearer platform on which subordinates could move forward, 
without "leaving them with too many questions." Through reflection, respondents were able to learn from 'mistakes' or experiences. Leaders enabled individuals to seek out answers themselves. Adjusting behaviours were illustrated by an interviewee who emphasised the importance of "resetting...hitting the hard, reset button in certain areas".

Theme 4: Influencing Through Networks and Appealing to Emotions: Interviewees reported that developing networks enabled them to gain knowledge, affording the opportunity to "learn from mistakes so as not to repeat them". The majority of respondents viewed networking as both an internal and external leadership function. By focusing on both internal and external networks, it increased the network's diversity. Interviewees established direct and indirect interpersonal communication to exert influence into the context. Awareness of context also played a role in this theme, for example, an interviewee explained the importance of, "staying abreast of where your environment is...create where you want to be going and what you want to be doing." Building relationships contributed to leaders being able to exercise wider social influence. A key aspect identified by the interviewees was that these relationships were primarily dependant on them having the "right people surrounding them, partnering with the right people". Another important aspect was connecting individuals to information in engendering empowerment and inspiration, for example, an interviewee observed "It's how you deal with what...so connecting information, employees with information...to wow them to inspiration." The empowerment of individuals fostered conditions for the development of organisational capacity for diversification.

Theme 5: Creating Feedback Loops and Initiating More Change: In terms of the capability for continuous change, interviewees reported that they initiated measurement or a feedback loop of how successful the diversification strategy had been and then initiated more change if required. One of the deciding factors to diversify even further was the driving force for competitive advantage. Interviews regarded sensitivity to context, as enabling them in decision-making on further diversification, for example on new products and expanding into yet another market. Interestingly, the interviewees were able to inspire others, by appealing to their emotions. They used storytelling to relate their own experiences in inspiring others. An interviewee warned for example, "...make decisions in that context, otherwise diversifying could be suicidal". A new level of functioning then requires another wave of change, through the creation of a "compelling vision" or "future state" to drive an organisation forward.

\section{Discussion}

Describing and Diagnosing Diversification Context: As mentioned under findings of research question one, interviewees in this sample, regarded their contexts as being highly complex and requiring continuous change. Pandya and Rao, (1998) suggest that for organisations to remain competitive, diversification was popular, especially in response to environmental changes. However, to diversify, organisations need to be able to rapidly and continuously change their offering into vectors, such as those outlined by Ansoff (1958), which invariably required new skills and techniques to enable them to change their structure and functioning. Scholars like Uhl-Bien, Marion and McKelvey (2007) also emphasised the complexity of context in the knowledge-era, requiring new approaches and continuous adaptation. In this regard, D' Aveni et al. (2010), concur that contemporary competitive advantage requires a cycle of creating, destroying and recreating, through strategic manoeuvring. The current study supports these previous research findings. The interviewees description of their dynamic context relates to the construct of a volatile, uncertain, complex and ambiguous (VUCA) environment (Bennet \& Lemoine, 2014).

Kutz (2008) also emphasises a conceptual understanding of multiple contextual variables, representing internal and external dimensions. The self-reflection or intrapersonal aspect was also mentioned by the interviews, as well as their awareness of others' emotions, that Kutz (2008) initial theory had not referred to. The current study likewise emphasised continuous change and adaption relating to diversification. Thomas and Greenberger, (1995) assert that having an orientation to time is a critical success factor in leadership and a driving force behind the firm performance. The interviewees in the current study also reported on their orientation to time. Zimbardo and Boyd (1999) explain the evolution of the notion of time, from Einstein's relativity theory to Heidegger's existential philosophy and Kurt Lewin's explanations on the influence of both the past and the future on current behaviour. Similarly, the contemporary social-cognitive thinking of Albert 
Bandura's (1997) classic self-efficacy theory, states that self-regulation is generated by efficacy beliefs grounded in past-experiences, as well as current appraisals and reflections on future options.

Cognitive psychologists like Carstensen, Isaacowitz and Charles (1999) emphasise that the perception of time plays a fundamental role in the selection of social goals. For example, when the time is perceived as openended, meaning future orientated, then people are more focused on gaining knowledge, but when the time is perceived as limited, emotional goals like focus on the family, are more important. The interviewees reported on their investment in the present to have an outcome in the future. These findings relate to another study that showed that when individuals assign more importance to the delayed future consequences of their behaviour than the immediate consequences, they are more responsible in taking financial decisions (Joireman, Sprott \& Spangenberg 2005). Moat, Olivola, Chater and Preis, (2014) report that there is a greater focus on the future in countries with a higher per capita GDP. While the sample was from South African organisations, where the country has a low GDP, the senior managers in this sample had a distinctive future orientation.

Translating Awareness into Context Knowledge: The concept of translating awareness into context knowledge was supported by Kutz and Bamford-Wade (2013), who described the idiom of transforming data into useful information, information into knowledge and knowledge into practice. Interviewees referred to the process of screening the information present within the environment, interpreting and cataloguing it for its relevance to the desired outcome of diversification. Prahalad and Bettis (1995) describe this cognitive process of interpreting the filtered information to ascertain if it applied to any relevant schema categories and Osborn et al. (2002) called this process the patterning of attention. Ericsson, Prietula and Cokely (2007), note that the ability to analyse actions and decisions in light of real outcomes requires a far-reaching interpretative system. Hastsopoulos and Hastsopoulos (1999) found that tacit understanding comes from two sources: experience and analogical reasoning. This sense-making process included self-reflection. Harrington and Loffredo, (2011) emphasise the importance of internal self-awareness or self-focused attention to one's feelings and mental processes for a greater sense of well-being that is generally used in mindfulness practices. Kutz and Bamford-Wade (2013) contend that the best source of tacit knowledge comes from experience, which enhances performance through tactile experience. Interviewees in this study also mentioned their immersion into context to gain exposure.

Influencing Others' Focus on Context: The thinking process above on deriving knowledge, went further than the individual leader. Interviewees described how they elicited involvement by defining boundaries and allowing employees to experiment. They injected ideas, which related to Uhl-Bien and Marion (2001) notion of leadership being able to foster conditions that develop organisational capacity, which instead of being control-driven, generated positive emergence and enabled bottom-up dynamics. The researchers observed that the knowledge that interviewees gained prompted them to act differently. Brown et al. (2005) emphasise in this regard that through contextual awareness leaders are able to adjust their style to the situation and their followers' needs. In the current study, interviewees also reported on the adjustment of their leadership styles. Interviewees observed a process of unlearning, likened to Rautenbach, Sutherland and Scheepers' (2015) notion of environmental triggers for the process of unlearning and relearning. It relates to the contextual variables highlighted in the current study.

Influencing through Networks and Appealing to Emotions: Interviewees appreciated that they did not know everything, enabling them to consciously go out and seek new information from people, to better understand their position within the operating context. Through this exposure, a process of reinvention or reimagination occurred that allowed them to adapt to the dynamics of the context and required diversification. This process spoke to the dimensions of the network development of Osborn et al. (2002). Lichtenstein et al. (2006) reason that to solve complex situations, a leader needs to bring individuals and groups around a problem, facilitating the flow and interaction to bring about the change, rather than self-imposing the answers. The majority of interviewees described networking as both an internal and external leadership function, providing for network diversity. This was in line with the original multiple influence models developed by Hunt et al. (1983) and expanded by Brass and Krackhardt (1999). It links closely to the relational perspective on the leadership of Uhl-Bien (2006), in which the focus is on relationships and not individuals; the combination of interacting relations and contexts are important. Day, (2001) contends that 
leadership is a social process. Leaders' story telling also linked to this relational aspect, since the emotional connection with employees enabled leaders to share those stories that inspired others.

Creating Feedback Loops and Initiating More Change: The interviewees reported that they had to investigate the real truth on the level of performance of their diversification strategy. They realised that diversification requires continuous change and as a result had to question the fundamentals on which their current strategies were based to ascertain where new mental models would be required. Prahalad and Bettis' (1986) views are relevant to this process since they emphasised that when leaders were asking relevant questions, it enabled individuals to scan environments selectively. The current study adds to current scholars' contributions, by pointing to interviewees' reports on using their judgment, in balancing the extension of the diversification strategy; and at other times reducing diversification, by maintaining the status quo. This careful consideration of the pace of diversification, was, however, not represented in the whole sample. A couple of the leaders appeared oblivious to the dangers of continuous change; for example they had not recognised change fatigue as a possible consequence of their diversification strategies. These characteristics of the sample assisted the researchers' understanding of the findings, since these types of diversification strategies would require continuous change. The need for consolidation and regrouping before more diversification is initiated, was unfortunately not recognised.

Managerial Implications: The study's findings suggest that leadership development must include examining organisations' external environment or environment of business' courses. Lectures should focus on the development of leaders' contextual intelligence, by analysing contextual variables. Organisations' investment in leadership development must thus include wider exposure to global trends in the market and opportunities that could be capitalised on. Selection processes of leadership must include the assessment of future orientation, as the interviewees' pointed to the importance of this attribute in leadership within diversifying organisations. Leadership will benefit from creating space in their busy schedules to reflect on influences from their business environment to inform their decision making around diversification. The findings of the current study show that an increase in the degree of diversification requires more change and the more complex the environment becomes. Since the organisations in the sample had various types of diversification strategies simultaneously, the complexity would have been high and thus required a higher degree of leadership attention as illustrated in the figure below.

Figure 1: Illustration of Increase in Complexity through Diversification Requires Leadership Attention

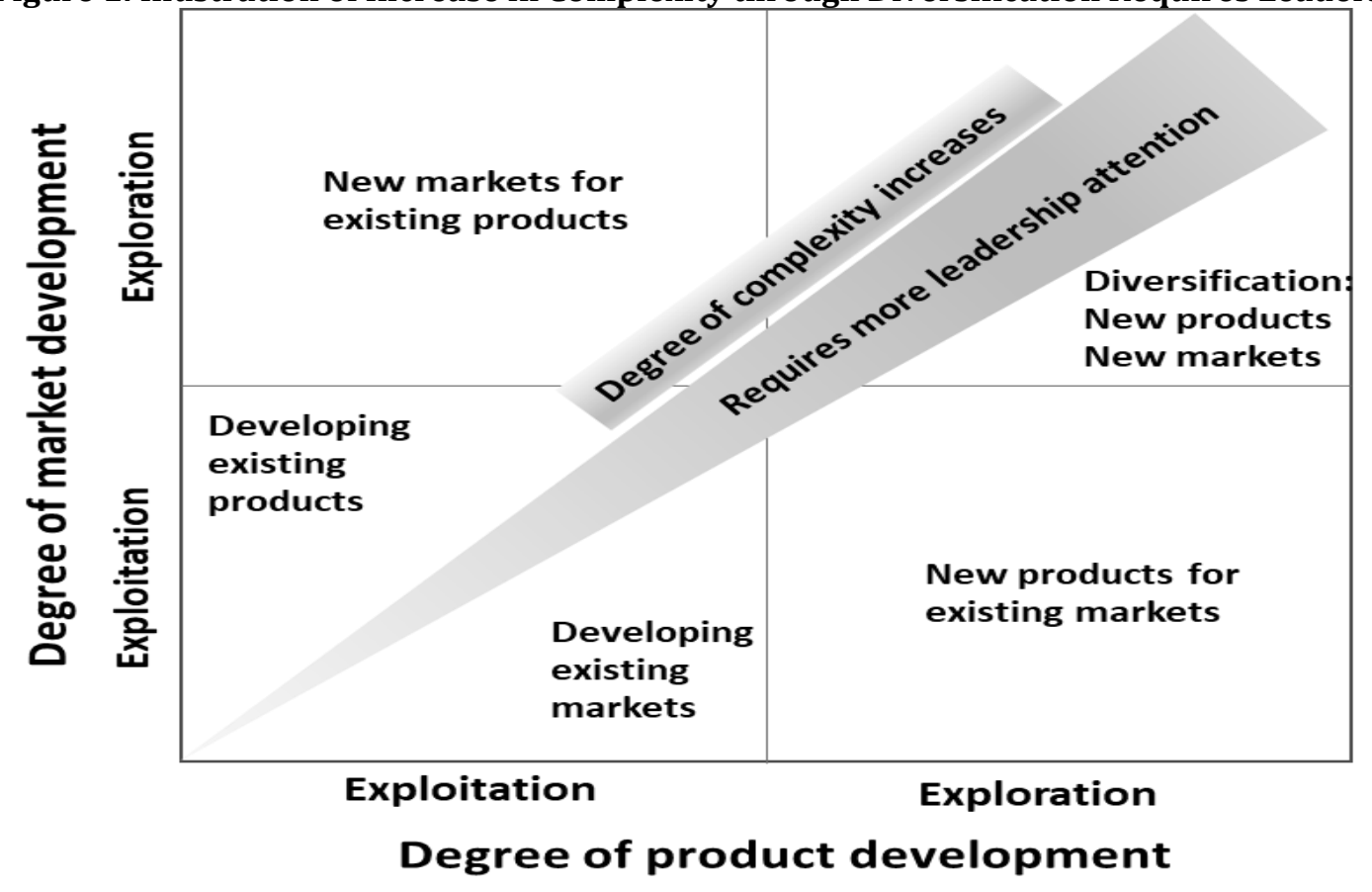

Source: Authors' own summary, based on Ansoff's (1988) framework 
The figure above illustrates the increase in complexity with the relating requirement of leaders paying attention to continuous change, especially in cases where the diversification strategy includes new products as well as new markets for these products. Failure in diversification might relate to leadership's lack of insight into these implications. The leaders who were interviewed in the present study played an important role in staying in touch with the external environment to seize opportunities. Leaders must stay in touch with their organisations and ensure that they include employees in diagnosis of context. The study revealed that luckily, leaders were sensing others' emotions and could ascertain when there is change fatigue present. In these cases, leadership must align the roll out plan of new diversification strategies, to the organisation's capacity to deal with more change. Leaders must thus ascertain the optimal pace of diversification.

The findings of this study provide leaders with a framework of thinking processes to enable successful diversification. For example, the findings encourage leaders to reach out to other leaders external to their organisation for exposure. An important finding was that leadership was required to regularly adjust their mindsets and own styles. Critical reflection played a crucial role here. A business coach offers mind space and facilitates leaders' discovering their own biases. It is in these moments of reflection and awareness that leaders see ways of challenging the status quo. For example, leaders must use information from their context to enable: either more diversification or time for consolidation prior to the next wave of diversification. The figure below illustrates the findings in the present study on the thinking processes of leaders' that enable diversification:

Figure 2: Illustration of Leaders' Cognitive Processes Enabling Diversification as a Continuous Reinforcing Cycle

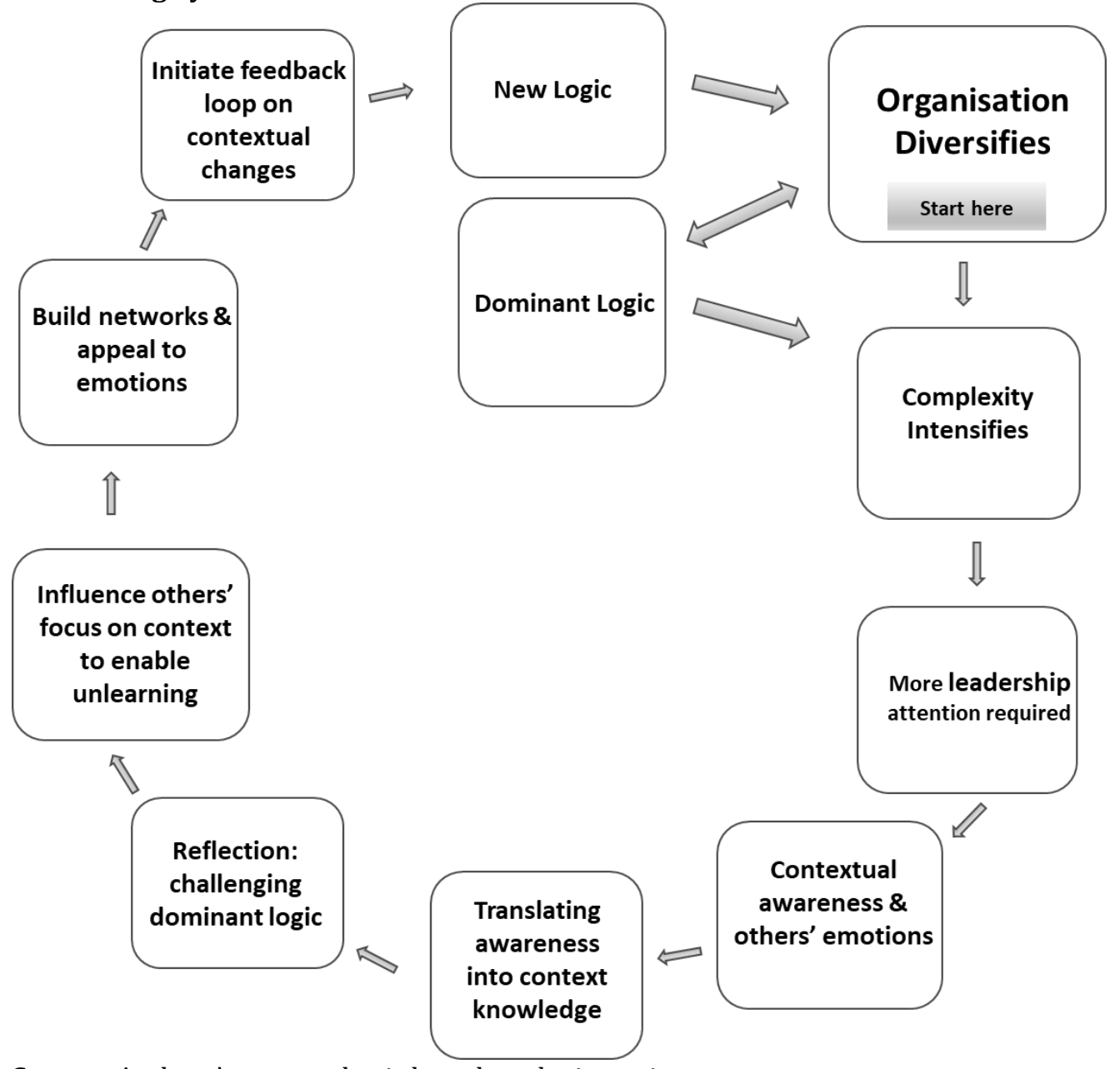

Source: Authors' own synthesis based on the interviews 
The figure above illustrates the concrete findings of this study: When an organisation diversifies, the first thinking process that is activated is dominant logic (as described by Prahalad and Bettis (2000)). This is the existing belief or schema of what makes an organisation successful. However, dominant logic was later on pronounced by Prahalad (2004) as not static, but dynamic. It is influenced by the diversification strategy, which in turn intensifies complexity in the environment. The increased complexity then requires more leadership attention. As the themes in the present study indicated, leaders had contextual awareness of the internal organisational and external market environment. In addition to Kutz (2008) perspective, the interviewees also reported on awareness of others' emotional needs. Another theme that was discussed above was the translation of awareness of context into knowledge. There are a range of thinking processes involved here, like filtering of information. A key thinking process is a reflection that enables leaders to compare their context knowledge with their existing schemata or mindsets. This process then results in challenging the dominant logic, which enables in turn, unlearning of current mind-sets.

In addition to the personal change in mind-sets, leaders purposefully inject ideas and patterning the attention of others to enable them to increase their awareness of context. This exposure challenges others' dominant logic and in turn, enables unlearning. Another key action that leaders take is exposing themselves and their teams to networks, also external to the organisation. In the final phase, leaders ensure a feedback loop on changes in the context, challenging the current dominant logic once again and through reflection, create a new aspirational cognitive map or new logic of what the future should look like. This might entail more diversification and would thus link the process with the previous cycle and create a spiral of increased intensity of change and complexity. Organisations could take cognisance of this reinforcing cycle to increase awareness and enable conscious choice on what the next phase of change should entail and manage the pace of change to ensure the organisation builds capacity for continuous change. Since globalisation requires globalized thinking (Ireland \& Hitt 2015), senior leaders must thus be aware of global trends (Bowen, Baker \& Powell, 2015). This exploratory research revealed that exposure contributed to lateral thinking and it follows that international educational experiences for South African senior leaders are essential.

Limitations and Suggestions for Future Research: The present study was limited to the perceptions of senior managers in the sample of organisations that diversified. While a valuable understanding of their thinking processes was gained in this study, future research could involve a sample of employees reporting to these managers. In this regard, scholars like Osborn et al. (2002) emphasise that leadership is embedded in its context and that different managerial levels experience their reality quite differently and these differences could be an interesting topic for future research. The current study was conducted in South Africa, with a unique history and contextual variables. Several organisations in this study diversified by exploring markets in other African countries, with mixed levels of success. The present study explored leaders' thinking processes where diversification was perceived to be successful. Future studies could compare organisations, where the diversification was a failure, to those where the diversification was successful, especially where the diversification included expansion to new markets in Africa. These future samples must also include objective data on performance as a result of the diversification, instead of relying on the perception of senior managers with vested interests in whether the diversification is successful.

Conclusion: The present study contributes to a deeper understanding of leaders' cognitive processes to enable diversification. The study highlights the importance of regular reflection. Leaders interviewed injected ideas and directed the attention of employees to relevant information. They inspired others by appealing to their emotions. The study offers insight into the mechanism to enable diversification, by keeping in touch with external contextual variables, such as international trends; and to feed this information back into the organisation to prompt more change towards diversification. 
Appendix: Table 3: Themes with Quotes from Interviews and Associated Literature

$\begin{array}{llll}\begin{array}{l}\text { Themes and Quotes } \\ \text { Codes }\end{array} & \text { Link } & \text { with } \\ & \text { Literature } & \end{array}$

\section{Perceptions on Diversification}

\begin{tabular}{|c|c|c|}
\hline $\begin{array}{l}\text { Types of } \\
\text { diversification: a } \\
\text { higher degree of } \\
\text { diversification }- \\
\text { increase } \\
\text { complexity }\end{array}$ & $\begin{array}{l}\text { Product development: "It's basically all metal in our products...so } \\
\text { all these products that we diversify into, all come from metal"; } \\
\text { "This year, we rebuilt our website, we wanted to diversify more } \\
\text { into online...so build less physical stores" }\end{array}$ & $\begin{array}{l}\text { Diversification as } \\
\text { growth strategy and } \\
\text { types } \\
\text { diversification of } \\
\text { (Ansoff, 1958; 1988) }\end{array}$ \\
\hline $\begin{array}{l}\text { Diversification } \\
\text { requires } \\
\text { direction: Why do } \\
\text { we diversify? }\end{array}$ & $\begin{array}{l}\text { "I think getting the 'why' right for me is very important because } \\
\text { the 'what' is there, it's factual, you need to get the results, but } \\
\text { "why"?"; } \\
\text { "We call it ring-fences: what we can control, what we can't control } \\
\text { and based on that what makes us ready to move" }\end{array}$ & $\begin{array}{l}\text { Insight of top } \\
\text { management to } \\
\text { choose the right } \\
\text { strategy (Prahalad } \\
\text { and Bettis, 1986) }\end{array}$ \\
\hline $\begin{array}{l}* \quad \text { Continuous } \\
\text { change required }\end{array}$ & $\begin{array}{l}\text { "For survival: you have to diversify and it's a continuous change, } \\
\text { it's that continuous moving, that keeps you alive"; } \\
\text { "We are working in fast-paced times, that changes every day"; } \\
\text { "How do you keep one step ahead of the curve?" }\end{array}$ & $\begin{array}{l}\text { Context } \\
\text { characteristic: VUCA } \\
\text { (Bennet r and } \\
\text { Lemoine, 2014); } \\
\text { Chakravarthy (1997) }\end{array}$ \\
\hline
\end{tabular}

\section{Leaders demonstrated being in touch with their context and others' emotions}

Cognitive awareness of complex context: Diagnosis context

Time orientation: Balance
"This whole inter-connectedness of life"; "Understanding who will affect me directly or indirectly; a stakeholder map";

"Your biggest brand ambassadors are your clients because they hold more data than anyone else."

"Only by what history has done can you plan forward"; "Understand the paradox: You need to look for now, and you still look into the long-term distance";

"You learn from your past, in terms of your life experiences";

"...to put context to what's relevant today and what needs to be done today, which will get you to where you're going";

"You are where you are today based on the sets of decisions you made to get there."

* Future time orientation: opportunity focus

Openness to new Immersion in context:
"Follow an evidence-based approach, to find out what's going on, and through which, to find a gap to create the opportunity for you";

"...to engender that inspiration, that passion, that fire that keeps on fuelling";

"You can make one-degree positive moves in anybody's life that can turn out to be $30 \%$ positive in three years' time";

"Be the game changer in your greater context"; "where you want this business to be";

"Creating a compelling enough story that people want to follow you"
Contextual

intelligence of Zeitgeist: Spirit of time (Mayo and Nohria, 2005); Diagnose context: Kutz and BamfordWade, 2013)

Time Perspective (Zimbardo and Boyd, 1999)

Convergence of past, present and future in 3-Dimensional thinking (Kutz, 2008)

Future focus leads to responsible financial decisions (Joireman, Sprott and Spangenberg, 2005)

Humility in 
information assisted

gaining knowledge
"Engaging and listening to people in your immediate space"; "I

in learn a lot from folks who have different backgrounds, perspectives";

"I enjoy, sort of, functioning with them (the team)"; "humility in the university of life";

"I have to be very aware of what's going on around me"; "my exposure to other leaders assisted me in gaining knowledge."

Reflection: conscious of the lens; metathinking

"It's the time to think, the time to connect the dots";

"You look back and you think I could have been better here";

"I have the ability to influence the lens, which I look through"; "Introspect as to why you're feeling that way and to look beyond the peripherals"

Self-knowledge: "I can be difficult, but also participative. I want the results"; "I don't particularly like networking"; "it's actually my weakness";

"I have the iron inside: unwavering determination"

* Sensing others' emotions and needs
"What is their appetite for really being stretched";

"Choose the right people within the team"; "knowing others' personally and their home situation"
Leadership vs Arrogance (Vera and Rodriguez-Lopez, 2004)

Self-awareness; insight that leads to wellbeing

(Harrington and Loffredo, 2011)

Emotional

Intelligence

(Goleman, 1996)

\section{Leaders demonstrated adaptability and influenced others' thinking and emotions}

Filtering information: Dominant Logic
"You got to manage your brain and that's why I call it cognitive load management"; "listening to others' way of thinking"; "assess what is important"; "give the organisation a sense of direction"

Patterning attention others

of "You need to teach people how to think";

of "the strategic dance";

"injecting ideas and brainstorming is incredibly important"

Courage to ask challenging questions: Dialogue conflict resolution

Building collaborative relationships across boundaries: Network Diversity Intentionally adjust leadership style
Connect others with networks: "Engaging with different industries, trying to see where there may be an opportunity"; "partnering with the right people"; "relationships in terms of finding a purpose/a joint purpose";

"finding out what people did wrong because you learn more from that than what people did right"

"I think you have to reimagine yourself"; "I have to really force myself to go to these events"; "I have to make a conscious effort to do it"; "That was outside of my comfort zone";

"I have a business coach"; "I can't control the market...but I can control the way I feel and the way I behave"; "I have chameleonlike behaviour"
Choosing relevant information;

Peripheral vision of Dominant logic (Bettis and Prahalad, 1995)

Patterning of attention (Osborn et al., 2002)

Encouraging different viewpoints (Kutz, 2008)

Enabling leadership (Uhl-Bien, Marion and McKelvey, 2007); Consensus builder (Kutz, 2008)

Social Capital (Arena and Uhl-Bien, 2015);

Building networks (Osborn et al., 2002); Communication

(Kenny, 2012)

Contextual intelligence consequences: adjustment (Nye, 2011); behavioural adjustment (Kutz, 
* Increase speed of learning: unlearning and relearning
Creating a safe environment: "Learning not to make the same mistake again";

"leaders must catalyse the collective reflection";

"give them the freedom to fail quickly and to relearn at the fastest rate";

"First, you need to define the boundaries, then let them play"; "freedom to be able to do what you need to do and make the rules that you need";

"You reflect - you learn and you unlearn. It's an iterative process"

* Appealing to others' emotions; enrolment through inspiration
Affective component: "connecting employees with information can 'wow" them"; "use storytelling";

"people are only willing to die for a cause, if it is their cause"; "use metaphor to explain: you take a telescope as if you're looking into a tunnel at different scenarios and you go back again, back and forth"
2008); fixing context: (Sternberg, 1988)

Unlearning

(Rautenbach, Sutherland and Scheepers, 2015); reflection on learning (Heyler, 2015)

Vision and inspiration from Transformational Leadership (Bass, 1985)

\section{Leaders enabled measurement and feedback and initiated more change}

Feedback loop "Understanding the fundamentals, the real truth and seeing where and New Logic and how we can be better"; Challenge Dominant Logic yet again:

"Reimagine...to start opening up one's mind to see things differently"

Balancing consolidation and more change
Use judgment on whether new wave of change is required: "Having an intimate knowledge of the context by within which we operate, and then being able to make decisions in that context, otherwise diversifying could be suicidal";

Timing of next wave of diversification: "Diversification doesn't necessarily mean adding continuously, but it's a balance of knowing when to add and sometimes you need to take away"
Behavioural logic: thinking, feeling and acting (Bettis and Wong, 2003)

High-performing individuals (Kenny, 2012); (Ansoff, 1958)

* The rows with an asterisk, indicate constructs not previously identified in relation to contextual intelligence and thinking processes during diversification

\section{References}

Ansoff, H. I. (1958). A model for diversification. Management science, 4(4), 392-414.

Ansoff, H. I. (1988). New corporate strategy. New York: John Wiley and Sons.

Arena, M. J. \& Uhl-Bien, M. (2016). Complexity Leadership Theory: Shifting from Human Capital to Social Capital. People and Strategy, 39(2), 22-29.

Azmi, F. (2008). Mapping the learn-unlearn model: Imperatives for strategic management. European Business Review, 20(3), 240-259.

Bandura, A. (1997). Self-efficacy: The exercise of control. Freeman, New York, NY.

Bass, B. M. (1985). Leadership and performance beyond expectations. Free Press, New York, NY.

Bennet, N. \& Lemoine, J. (2014). What VUCA really means for you. Harvard Business Review, 92(1/2), 27.

Bettis, R. A. \& Prahalad, C. K. (1995). The Dominant Logic: Retrospective and Extension. Strategic Management Journal, 16(1), 5-14.

Bettis, R. A., Hall, W. K. \& Prahalad, C. K. (1978). Diversity and performance in the multibusiness firm. National Proceedings of the American Institute for Decision Sciences, 210-212.

Bettis, R. A. \& Hitt, M. (1995). The new competitive landscape. Strategic Management Journal, $16,7-19$. 
Bettis, R. \& Wong, S. (2003). Dominant Logic, Knowledge Creation and Managerial Choice. In M. EsaterbySmith, \& M. Lyles, Handbook of Organizational Learning and Knowledge Management, 343-355.

Blass, F. R. \& Ferris, G. R. (2007). Leader Reputation: The Role of Mentoring, Political Skill, Contextual Learning and Adaptation. Human Resource Management, 46(1), 5-19.

Bowen, H. P., Baker, K. H. \& Powell, G. E. (2015). Globalization and diversification strategy: A managerial perspective. Scandinavian Journal of Management, 31(1), 25-39.

Brass, D. J. \& Krackhardt, D. (1999). The social capital of twenty-first-century leaders in J. Hunt, Dodge, G. R. \& Wong, L. Out-of-the-box leadership: Transforming the twenty-first-century army and other topperforming organizations, Stamford, Conn: Jai Press, 179-194.

Brown, S. L. \& Eisenhardt, K. M. (1997). The art of continuous change: Linking complexity theory and timepaced evolution in relentlessly shifting organizations, Administrative science quarterly, 1-34.

Brown, C. H., Gould, D. \& Foster, S. (2005). A framework for developing contextual intelligence. The Sports Psychologist, 19(1), 51-62.

Burns, J. (2002). Chaos theory and leadership studies: exploring uncharted seas. Journal of Leadership and Organizational Studies, 9(2), 42-57.

Carstensen, L. L. \& Isaacowitz, D. M. \& Charles, S. T. (1999). Taking time seriously: A Theory of socioemotional selectivity, American Psychologist, 54(3), 165-181.

Chakravarthy, B. (1997). A new strategy framework for coping with turbulence. Sloan Management Review, Winter, 69-82.

Chandler, A. (1990). Strategy and structure (Vol. 4). MIT Press, Cambridge.

Creswell, J. (2014). Research design: Qualitative, quantitative, and mixed methods approach (4th Edition ed.), Sage, Thousand Oaks, California.

D'Aveni, R. A. (1994). Hyper-competition - Managing the dynamics of strategic manoeuvring. Harvard Business School Press, Boston.

D'Aveni, R. A., Dagnino, G. B. \& Smith, K. G. (2010). The age of temporary advantage, Strategic Management Journal, 31(13), 1371-1385.

Day, D. V. (2001). Leadership development: A review in context. Leadership Quarterly, 11(4), 581-613.

Drejer, A. (2004). Back to basics and beyond: Strategic management - an area where practice and theory are poorly related. Management Decision, 42(3/4), 508-520.

Ericsson, K., Prietula, M. \& Cokely, E. (2007). The Making of an Expert. Harvard Business Review, 85(7/8), 114121.

Flanagan, J. C. (1954). The critical incident technique. Psychological Bulletin, 51(4), 327-357.

Frisinia, M. \& Frisinia, R. (2011). Correcting your leadership "Zero": Aligning your behaviour with your mission, vision, and values. Employment Relations Today, 38(1), 27-33.

Goleman, D. (1996). Emotional Intelligence: Why it can matter more than IQ. Bloomsbury, London.

Grant, R. M. (1988). On 'dominant logic. Relatedness and the link between diversity and performance. Strategic Management Journal, 9(6), 639-642.

Guest, G., Bruce, A. \& Johnson, L. (2006). How many interviews are enough? An experiment with data saturation and variability. Field Methods, 18(1), 59-82.

Harrington, R. \& Loffredo, D. A. (2011). Insight, Rumination, and Self-Reflection as Predictors of Well-Being, The Journal of Psychology, 145(1), 39-57.

Hastsopoulos, N. \& Hastsopoulos, G. (1999). The role of tacit knowledge in management. In R. Sternberg, \& J. Horvath, Tacit Knowledge in Professional Practice: Researcher and Practitioner Perspectives (pp. 141-152). Mahwah, NJ: Lawrence Erlbaum Associates.

Heifetz, R. A. (1998). Leadership Without Easy Answers. USA: Harvard University Press.

Heyler, R. (2015). Learning through reflection: the critical role of reflection in work-based learning (WBL). Journal of Work-Applied Management, 7(1), 15-27.

HSBC. (2016). What are emerging markets? https://investorfunds.us.hsbc.com/investing-in-emergingmarkets/map-at-night/default.fs (accessed 29 Sep 2017).

Hunt, J. G., Osborn, R. N. \& Martin, H. J. (1983). A multiple influence model of leadership. Alexandria, VA: Army Research Institute.

Hutzschenreuter, T. \& Horstkotte, J. (2013). Performance effects of top management team demographic fault lines in the process of product diversification, Strategic Management Journal, 34, 704-726.

Ireland, D. \& Hitt, M. (2005). Achieving and maintaining strategic competitiveness in the 21st century: The role of strategic leadership. Academy of Management Executive, 19(4), 63-77. 
Jarzabkowski, P. (2001). Dominant Logic: An aid to strategic action or a predisposition to inertia. Aston Business School Research Institute.

Joireman, J., Sprott, D. E. \& Spangenberg, E. R. (2005). Fiscal responsibilities and the consideration of future consequences, Personality and Individual Differences, 37, 1159-1168.

Kellerman, B. (2013). Leading questions: The end of leadership - redux. Leadership, 9(1), 135-139.

Kenny, G. (2012). Diversification: best practices of the leading companies. Journal of Business Strategy, 33(1), 12-20.

Kofman, F. \& Senge, P. (1993). Communities of commitment: The heart of learning organizations. Organizational Dynamics, 22(2), 4-23.

Kor, Y. Y. \& Leblebici, H. (2005). How do interdependencies among human-capital deployment, development, and diversification strategies affect firms financial performance? Strategic Management Journal, 26(10), 967-985.

Kutz, M. (2008). Toward a conceptual model of contextual intelligence: a transferable leadership construct. Kravis Leadership Institute Leadership Review, 8, 18-31.

Kutz, M. \& Bamford-Wade, A. (2013). Understanding Contextual Intelligence: A Critical Competency For Today's Leaders. Emergence: Complexity and Organization, 15(3), 55-80.

Lampel, J. \& Shamsie, J. (2000). Probing the unobtrusive link: Dominant logic and the design of Joint Ventures at General Electric. Strategic Management Journal, 21, 593-602.

Lau, C. M. (1993). Diversify with care: Diversification strategies and organization development. The International Journal of Organizational Analysis, 1(1), 55-72.

Levy, M. (2007, July-August). Look to Your Front Line for the future. Harvard Business Review, 55.

Lichtenstein, B. B., Uhl-Bien, M., Marion, R., Seers, A., Orton, J. \& Schreiber, C. (2006). Complexity leadership theory: An interactive perspective on leading in complex adaptive systems. Emergence: Complexity and Organization, 8(4), 2-12.

Lord, R. G. \& Maher, K. J. (2002). Leadership and information processing: Linking perceptions and performance. Boston, MA: Unwin Hyman.

Marx, T. G. (2013, December 12). Teaching leadership and Strategy. Business Education Innovation Journal, $5(2), 12$.

Mayo, A. J. \& Nohria, N. (2005). Zeitgeist Leadership. Harvard Business Review, 83(10), 45-60.

Moat, H. S., Olivola, C. Y., Chater, N. \& Preis, T. (2014). Searching choices: Quantifying decision-making processes using search engine data, Topics in Cognitive Science, 8, 685-696.

Mumford, M. D., Zaccaro, S. J., Harding, F. D., Jacobs, T. O. \& Fleishman, E. A. (2000). Leadership skills for a changing world: Solving complex social problems, The Leadership Quarterly, 11(1), 11-35.

Nye, J. S. (2011, July). Leadership, Power and Contextual Intelligence. Retrieved from The European Financial.

Osborn, R. N. \& Marion, R. (2009). Contextual leadership, transformational leadership and the performance of international innovation seeking alliances. The Leadership Quarterly, 20(2), 191-206.

Osborn, R. N., Hunt, J. G. \& Jauch, L. R. (2002). Toward a contextual theory of leadership. The Leadership Quarterly, 13(6), 797-837.

Pandya, A. M. \& Rao, N. V. (1998). Diversification and firm performance: An empirical evaluation. Journal for financial and strategic decisions, 11(2), 67-81.

Penrose, E. T. \& Pitelis, C. (2002), The growth of the firm: the legacy of Edith Penrose, Oxford University Press on Demand.

Prahalad, C. K. (2004). The Blinders of Dominant Logic. Long Range Planning, 37(2), 171-179.

Prahalad, C. K. \& Bettis, R. (1986). The Dominant Logic: A New Linkage between Diversity and Performance. Strategic Management Journal, 7(6), 485-501.

Punch, K. (2002). Developing Effective Research Proposals. London: Sage.

$\mathrm{Qu}$, S. Q. \& Dumay, J. (2011). The qualitative research interview. Qualitative Research in Accounting \& Management, 8(3), 238-264.

Ramanujam, V. \& Varadarajan, P. (1989). Research on corporate diversification: a synthesis', Strategic Management Journal, 10(6), 523-551.

Rautenbach, R., Sutherland, M. \& Scheepers, C. B. (2015). The process by which executives unlearn their attachments in order to facilitate change, South African Journal of Labour Relations, 39(2),145-164.

Robinson, O. C. (2014). Sampling in Interview-Based Qualitative Research: A Theoretical and Practical Guide. Qualitative Research in Psychology, 11, 25-41. 
Rumelt, R. (1974). Strategy, Structure and Economic Performance, Harvard University, Boston, MA: Division of Research.

Saunders, M. \& Lewis, P. (2012). Doing Research in business and management: an essential guide to planning your project. England: Pearson education limited.

Spiggle, S. (1994). Analysis and interpretation of qualitative data in consumer research. Journal of Consumer Research, 21(3), 491-503.

Stern, I. \& Henderson, A. (2004). Within-business diversification in technology-intensive industries. Strategic Management Journal, 25(5), 487-505.

Sternberg, R. (1996). Myths, counter-myths, and truths about intelligence. Educational Researcher, 25(92), 11-16.

Tetenbaum, T. \& Laurence, H. (2011). Leading in the chaos of the 21st century. Journal of Leadership Studies, $4(4), 41-44$.

Thomas, P. \& Greenberger, D. B. (1995). The relationship between leadership and time orientation. Journal of Management Inquiry, 4(4), 272-292.

Tsang, E. \& Zahra, S. (2008). Organizational unlearning. Human Relations, 61(10), 1435-1462.

Uhl-Bien, M. (2006). Relational leadership theory: Exploring the social processes of leadership and organizing. The Leadership Quarterly, 6, 654-676.

Uhl-Bien, M. \& Marion, R. (2009). Complexity leadership in bureacratic forms of organizing: A meso model. The Leadership Quarterly, 20(4), 631-650.

Uhl-Bien, M., Marion, R. \& McKelvey, B. (2007). Complexity leadership theory: Shifting leadership from the industrial age to the knowledge era. The Leadership Quarterly, 18(4), 298-318.

Vera, D. \& Rodriguez-Lopez, A. (2004). Strategic virtues: Humility as a source of competitive advantage. Organizational Dynamics, 33(4), 393-408.

Vermeulen, F. \& Barkema, H. (2002). Pace, rhythm, and scope: process dependence in building a profitable multi-national corporation. Strategic Management Journal, 23(7), 637-653.

Von Krogh, G. \& Roos, J. (1996). A Tale of the Unfinished. Strategic Management Journal, 17, 729-737.

Weeks, R. (2007). Context: The Strategic Management Rosetta Stone. Acta Commercii: Independent Research Journal in the Management Sciences, 7(1), 294-306.

Zimbardo, P. G. \& Boyd, J. N. (1999). Putting time in perspective: A valid, reliable individual-differences metric. Journal of Personality and Social Psychology, 77(6), 1271-1288. 